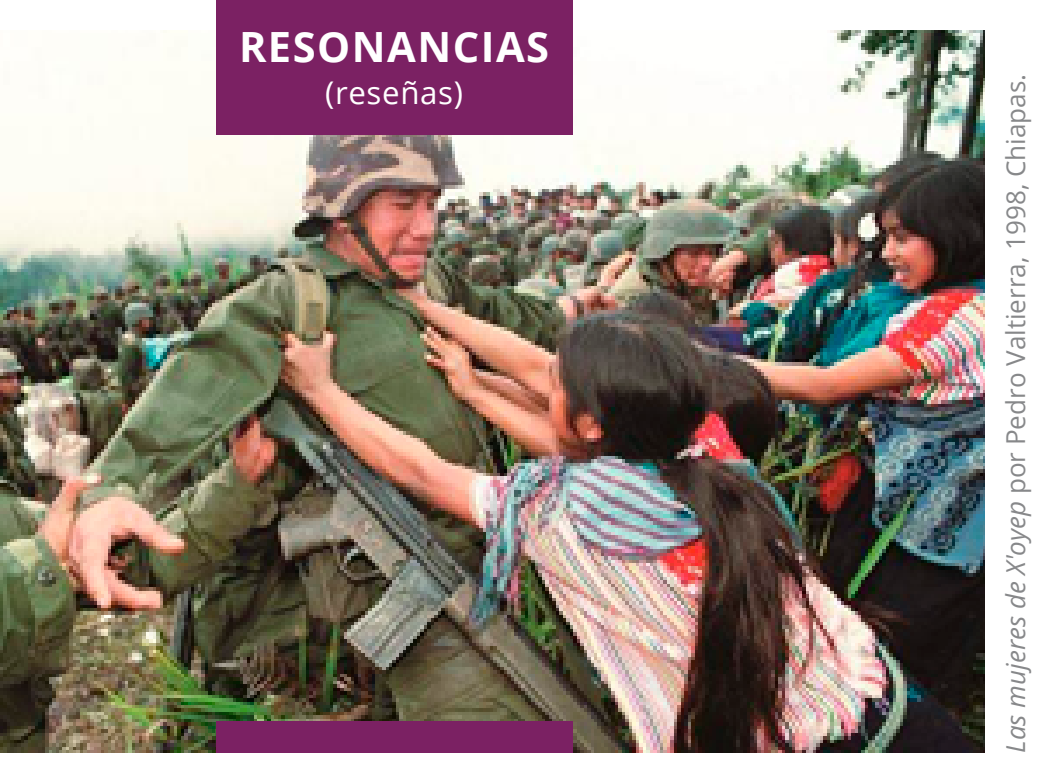

FIGURAS REVISTA ACADÉMICA DE INVESTIGACIÓN ISSN 2683-2917

Vol. 2, núm. 3, julio-octubre 2021

https://doi.org/10.22201/fesa.figuras.2021.2.3

Esta obra está bajo una licencia

Creative Commons Atribución-NoComercial-

Compartirlgual 4.0 Internacional

\section{Un nuevo contenido para los derechos humanos con experiencias del Sur global}

\section{New content for human rights with global south experiences}

https://doi.org/10.22201/fesa.figuras.2021.2.3.169

Isaac de Paz-González

Universidad Autónoma de Baja California. Facultad de Derecho, Tijuana

Se analiza el libro El pluriverso de Derechos Humanos. La diversidad de las luchas por la dignidad y sus aportaciones a la discusión de-constructiva de la eficacia de los derechos humanos. Se destaca que los trabajos contribuyen a un diálogo horizontal entre pensadores, actores y sobrevivientes de violaciones de derechos humanos.
Boaventura de Sousa Santos es un referente del Sur global sobre las nuevas epistemologías pensadas por y para los pueblos que no han participado en los esquemas de creación ontológica del pensamiento "occidental" que propicia una visión monolítica de los derechos humanos y su pretendida universalidad de leyes y discurso político superficial. Los trabajos de Boaventura se caracterizan por romper los esquemas convencionales de las filosofías coloniales dominantes y por tener un enfoque contra-hegemónico como parte de una nueva filosofía política que comprende la justicia, el humanismo y el conocimiento global.

La obra reseñada lleva por título: El pluriverso de Derechos Humanos. La diversidad de las luchas por la dignidad. Se trata de una colección de 21 ensayos editados por de Sousa Santos y Bruno Sena Martins. Como comentario inicial, bien se puede afirmar que el libro se inserta en los estudios de alteridad que dan cuenta de las narrativas impulsadas por las concepciones humanistas y experiencias del Sur global y a la crítica de los derechos humanos y que cada vez más van adquiriendo difusión y comprensión (Dussel 2015; Baxi 2007). Los ensayos se dividen en dos ejes: el primero es la "frontera de lo humano" y el segundo es de "luchas y emergencias". El trabajo que claramente se une a esa línea de pensamiento crítico del Sur global encargado de reivindicar las cosmogonías americanas sobre las que se erigen como contrapeso a los pre-conceptos de derechos humanos. El conocimiento que presenta el libro da testimonios de pensadores de Portugal, Hispanoamérica, India y Sudáfrica. Hasta ahora, las ideas del Sur global han sido desoídas principalmente en la clásica y eurocéntrica visión de los derechos humanos; y es desde esta férrea crítica que, se afirma, con alusión a Descartes, que el "'Yo pienso, luego existo' se acepta habitualmente como hito fundacional de la producción de conocimiento occidental [...] como el posicionamiento de los occidentales en tanto 'maestros perpetuos', pues aquí ese 'yo' es realmente un 'yo imperial'." (Madlingozi 2019, 256). 


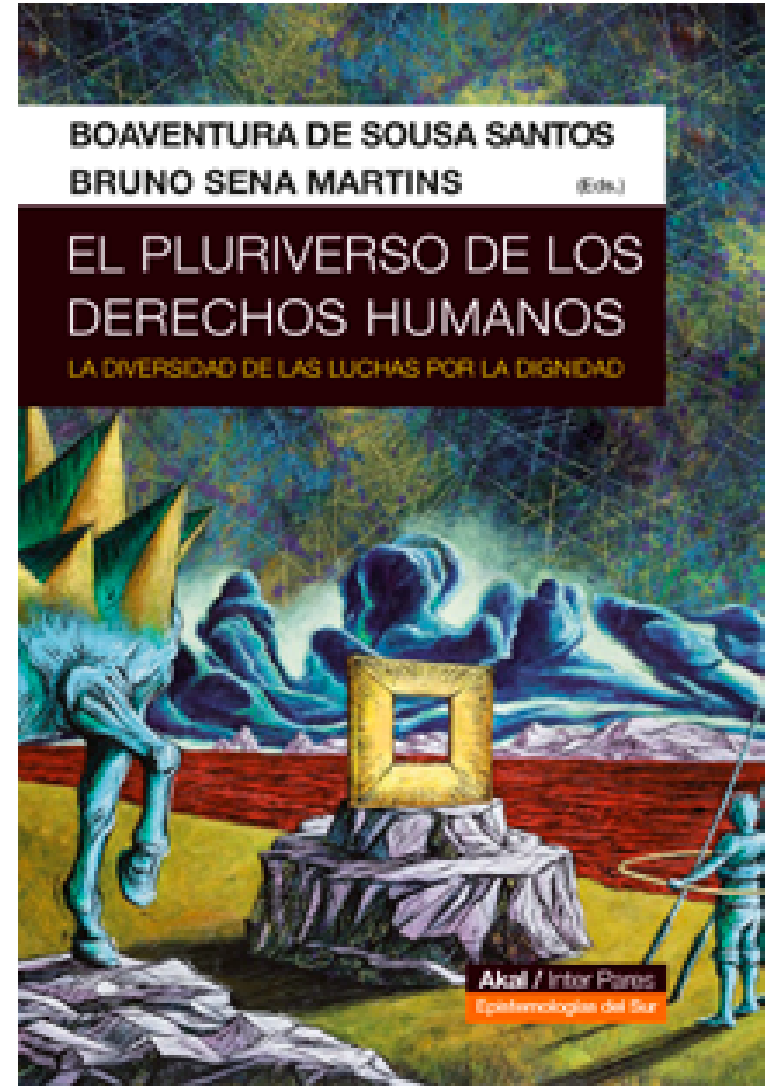

Portada del libro El pluriverso de los Derechos Humanos. La diversidad de las luchas por la dignidad de editorial Akal / Inter Pares.

La alusión a Descartes tiene el propósito de ilustrar la incesante respuesta al colonialismo en que los autores posicionan sus ensayos al tomar un esquema clásico desde la lucha cotidiana de los derechos humanos mediante constantes poco conocidas y analizadas en la literatura hispana e iberoamericana: la relación de la pobreza como consecuencia y factor potencial de la violación de derechos humanos, el abuso del poder corporativo y las violaciones graves a los derechos humanos de las mujeres.

La primera parte contiene los siguientes trabajos: El capítulo i se enfoca en los derechos humanos, democracia y desarrollo, fue escrito por Boaventura de Sousa Santos; el capítulo II, expuesto por João Arriscado Nunes, se titula: "Un ser que no ha sido hecho para sufrir: de la diferencia de lo humano y las diferencias de los humanos"; el capítulo III, -expuesto por Nelson Maldonado-Torres-, explica la colonialidad de los derechos humanos; en el IV, Juan José Tamayo realiza una apología del diálogo ante los fundamentalismos. Esta primera parte termina con el capítulo v: "Vivir como un ser social. La interconectividad del ser", escrito por Arzu Merali.

Los denominadores comunes de los cinco ensayos son el nuevo esquema humanista que intenta alejarse de las concepciones antropocéntricas; por un lado, la visión conceptual inclusiva para hacer del debate de los derechos humanos un círculo virtuoso y alejarse de la verticalidad colonial; $y$, por el otro, la necesidad de entablar un diálogo comunitario.

En la segunda parte, titulada "Luchas y emergencias", a partir de diversos casos de violaciones graves a los derechos humanos, los ensayos muestran que el diálogo actual y la reconstrucción epistemológica de los derechos humanos tiene una columna vertebral de la India. Los cuatro primeros trabajos de esta segunda parte, capítulo VI, "El desastre de Bhopal, derechos humanos y la memoria abismal" escrito por Bruno Sena Martins; el capítulo vII, "El pluralismo y la condición posminoritaria: reflexiones sobre el discurso 'musulmán pasmanda' en el norte de India"; el de Khalid Anis Ansari expone en el capítulo viII, un "Argumento a favor de las escalas de subalternidad: por qué Goa es importante para la teoría"; y capítulo Ix que contiene el trabajo sobre la violencia sexual contra las mujeres escrito por Pratiksha Baxi, "Imágenes de la ley, la reforma y la violencia sexual: notas sobre las protestas de 2012-2013 en Delhi".

Aquí hago una breve digresión por lo importante que resultan tanto las aportaciones teóricas como las fácticas de los primeros tres ensayos de la segunda parte. Y es que muchos de los trabajos publicados en México sobre la temática de los derechos humanos se enfocan únicamente en el estudio de las normas, las interpretaciones legales o constitucionales y a veces logran conjugar los estudios sociológicos del derecho; pero poco se conocen las narrativas de derechos humanos de otros contextos parecidos a México: países 
con historias coloniales, discriminación y pobreza estructural y con un rampante neo-liberalismo que nos iguala en el sufrimiento, la corrupción política y la herencia colonial discriminante. Es por ello por lo que, en esta parte, los ensayos sobre la India muestran casos y situaciones que padecemos en México: la ausencia de mecanismos de responsabilidad de las empresas que causan la muerte y el desplazamiento de seres humanos por la negligencia de la producción en masa. El desastre de Bophal, ocurrido en 1984, fue una muestra de cómo una empresa filial de Dow Chemical de pesticidas logró la impunidad y hasta la fecha se ha negado a pagar los daños humanos y ambientales provocados (Sena 2019, 161).

Otra constante de los casos que se analizan en el segundo bloque de trabajos proviene de la India, en particular, problemas de violencia sexual contra mujeres. El asunto expuesto en el capítulo IX de las protestas masivas de 2012-2013 en Nueva Delhi narra las problemáticas urbanas y sociales, y muestra los cuestionamientos a la violencia masculina que se consiente desde las estructuras sociales en la India. Y aquí el autor toca un punto álgido:

Se trata de una poderosa crítica al 'vacío cognitivo' de los discursos feministas, ya que las protestas no lograron traducirse en una epistemología de solidaridad. Identifica la carga, impuesta a las víctimas de violencia, de denunciar ante la policía o hablar en el trabajo, con independencia de que quiera o no hacerlo de ese modo (Baxi 2019, 243).

Los capítulos subsecuentes son: capítulo x, "La coexistencia pluralista de Steve Biko 'después' del conflicto", escrito por Tshepo Madlingozi; el capítulo XI, "Violencia política y formación del Estado en el África post-colonial", escrito por Mahmood Mamdani; el capítulo XII, "Mujeres y violencia masiva en Mozambique a finales del periodo colonial", por Maria Paula Meneses; junto con el capítulo XIII, "Derechos humanos de las mujeres: movilización legal y Epis- temologías del Sur", de Cecilia Macdowell Santos, que se complementa con el capítulo XIV, "Derechos humanos y la justicia étnico-racial en América Latina", de César Rodríguez Garavito y Carlos Andrés Baquero. Finalmente, este bloque de capítulos muestra el XV, "Existiendo, resistiendo y re-existiendo: mujeres indígenas ante sus derechos", de Begoña Dorronsoro.

Considero que este bloque de capítulos sobre derechos humanos y el papel de las mujeres en su vindicación que contiene El pluriverso de Derechos $\mathrm{Hu}$ manos marcará el inicio de un diálogo epistémico y de-constructivo del papel de las mujeres como sobrevivientes y forjadoras de luchas de los derechos humanos mediante el litigio, la Academia y la discusión global. Ante la falta de puente entre los aspectos normativos de las leyes nacionales e internacionales y el verdadero disfrute de los derechos en sociedades que han impuesto barreras, estereotipos y sistemas de dominación en contra de las mujeres, el trabajo propone que las mujeres han dado un significado a los derechos humanos mediante sus litigios ante diversos sistemas de derechos humanos: en cortes nacionales, ante el sistema interamericano con diversas técnicas, conocimientos y movilización jurídica trasnacional (Macdowell 2019, 326). Más adelante apunta una de las aportaciones que seguramente tendrá eco en otros trabajos de todo tipo, pues afirma que:

La investigación y la defensa jurídica de los derechos humanos y los derechos humanos de las mujeres no sólo debe prestar atención a los impactos materiales de la movilización jurídica, sino también a las interacciones entre los actores involucrados y sus experiencias subjetivas, ampliando la opinión aceptada en general sobre quién debe ser considerado defensor de los derechos humanos (MacDowell 2019, 343).

Así, se expone que las luchas, tanto de las mujeres como de los pueblos históricamente discriminados, 
han desembocado en varias respuestas y estrategias jurídicas nacionales y supranacionales ante los órganos típicos: cortes de justicia, cortes regionales y órganos de los tratados de derechos humanos de la oNU. Hay una propuesta conceptual que llama la atención: la respuesta del Multiculturalismo contra-hegemónico, de acuerdo con la siguiente vertebración que propone el capítulo de Rodríguez y Baquero $(2019,362)$ :

\section{Multiculturalismo contra-hegemónico:}

- Reclamo central: Diversidad/ igualdad material.

- Principio rector: Autodeterminación con reparaciones.

- Paradigma jurídico: Reparación.

- Estatus jurídicos de indígenas y afrodescendientes: Sujetos de derechos colectivos.

- Tiempo privilegiado: Pasado-futuro.

- Instituciones jurídicas representativas: Consentimiento previo, acciones afirmativas.

- Fuentes: Declaración de las Naciones Unidas sobre los derechos de los pueblos indígenas; Declaración deDurban,jurisprudencia(CIDH,Colombia,Brasil); constituciones pluriculturales (Bolivia, Ecuador); Convenio 169 (interpretación expansiva).

- Actores centrales: organizaciones indígenas y afrodescendientes, organismos ONU, relatorías, pueblos indígenas.

Finalmente, este bloque de capítulos también reconoce el valor de las mujeres en la construcción de otras formas de organización política que reivindican los derechos. Se afirma que

[...] las comandantas Ramona, Esther o Susana han simbolizado a las mujeres indígenas que en Chiapas están abriendo nuevos caminos que concretaron en la Ley Revolucionaria de las Mujeres Zapatistas y que siguen avanzando en el proceso.
Mujeres indígenas también han formado parte esencial de levantamientos y protestas contra los malos gobiernos de México y fueron especialmente reprimidas en Atenco y Oaxaca (Dorronsoro 2019, 391).

Como lo apunta Dorronsoro, las mujeres indígenas han estado al frente de las luchas asimétricas en contra del poder corporativo, militar y político en las regiones urbanas y en la selva. Pero también se han enfrentado a las posturas oficiales y lograron visibilizar otros frentes de los derechos humanos tanto en México como en el mundo (como Tita Radilla, Digna Ochoa, Lydia Cacho o las madres de las niñas asesinadas en el caso Campo Algodonero de Ciudad Juárez).

El bloque de capítulos que se refiere a las aportaciones de las mujeres es una muestra de las que llevan a cabo las del Sur global. La incorporación del multiculturalismo y la nueva justicia contra-hegemónica lograría disminuir la visión vertical de los derechos humanos impuesta desde los grandes centros de pensamiento que actualmente han vaciado de contenido la retórica de los derechos civiles. Pensemos, por ejemplo, el caso de Estados Unidos, en donde las asociaciones civiles y los centros de estudios de la Ivy League tienen poco interés en los temas de la justicia racial, a pesar de que Estados Unidos es un país donde existen severas violaciones a las minorías raciales y tienen miles de casos de mujeres indígenas desaparecidas en Phoenix, Alaska, Washington y otros estados (Departamento de Estado 2021, 26-36).

El último bloque de capítulos es el siguiente: capítulo XVI, "El derecho a la ciudad frente a las Epistemologías del Sur: reflexiones en torno al proceso brasileño de construcción del derecho a la ciudad", de Eva García Chueca; el capítulo XVII, "El poder del racismo en la academia: producción de conocimiento y disputas políticas" escrito por Marta Araújo y Silvia R. Maeso; el capítulo XVIII, "La memoria colectiva romaní y los límites epistemológicos de la historiografía occidental", de Cayetano Fernández; el capí- 
tulo XIX, "Derechos, confinamiento y liberación. La teoría de la retaguardia y Freedom of Movements", por Julia Suárez-Krabbe; el capítulo xx, "Desalinear abismos en el reverso de lo moderno: perspectivas feministas postcoloniales para un 'pensamiento alternativo de las alternativas'", de Catarina Martin; y el capítulo XxI, "Fronteras a la humanidad: nuestro Mediterráneo común construido como confín de los derechos humanos en la UE", de Ángeles Castaño Madroñal.

En este último bloque destaca el tema del racismo en la Academia. Se formula una crítica a los métodos de investigación que aluden a espacios urbanos seleccionados con la intención de identificar grupos étnicos mediante prejuicios sobre los otros como objeto de estudio (Araujo y Maeso 2019, 431-433). En esta parte es muy relevante apuntar que en distintas universalidades se han gestado movimientos de crítica a las aportaciones de figuras históricas como Woodrow Wilson, que tienen un legado cuestionable (Araujo y Maeso 2019, 440), pero que son ensalzadas en los contextos universitarios.

En esta breve panorámica de la obra reseñada intento mostrar los indicadores emergentes de una visión distinta de los derechos humanos, de su construcción epistemológica desde el sur y de las aportaciones de diversos grupos a los que no se les da voz comúnmente. Por otro lado, debo decir que la lectura de El pluriverso de Derechos Humanos. La diversidad de las luchas por la dignidad es una lectura global de referentes imprescindibles en los debates transdisciplinarios e interdisciplinarios de las ciencias sociales y las humanidades para lograr una comprensión anclada a la necesidad de re-orientar el discurso de los derechos humanos con un carácter plural e incluyente. Por ejemplo, una de las destacadas autoras es Maria Paula Meneses, de la Universidad de Coímbra, quien ha realizado trabajo de campo en Angola, Mozambique y Sudáfrica. Otra es Julia Suárez-Krabbe, impulsora de las metodologías de investigación de-colonizantes y sobre la necesidad de impulsar un diálogo horizontal entre las universidades del Norte con las del Sur global.

En suma, la obra reseñada constituye una invitación a replantear el estudio de los derechos humanos desde las perspectivas de los sobrevivientes y las cosmogonías originadas en amplios conceptos de los derechos que se apartan de la lógica integracionista en la que ya todo está dicho. Considero que la visión feminista de los derechos de los pueblos originarios que luchan frente a las empresas y los proyectos extractivos y la discusión constituyen una luz en el oscuro camino de los derechos. Por lo demás, este libro es referencia obligada para quienes estudian la construcción epistémica de los derechos, el género y las desigualdades estructurales e incluso para comprender la importancia de las voces de las víctimas en su entorno social. -

\section{Referencias}

Baxi, Upendra. 2007. Human Rights in a Post Human World: Critical Essays. Oxford: Oxford University Press.

De Sousa Santos, Boaventura y Bruno Sena Martins eds. 2019. El pluriverso de Derechos Humanos. La diversidad de las luchas por la dignidad, ARGENTINA- ESPAÑAMÉXICO: Akal.

Department of Justice. 2021. Missing or Murdered Indigenous Persons: Law Enforcement \& Prevention vol. 69, no.1. https://www.justice.gov/usao/page/file/1362691/ download Revisado el 31 de mayo, 2021.

Dussel, Enrique. 2015. Filosofías del Sur. Descolonización y transmodernidad. México: Akal. 